\title{
A Prospective Study: Is Routine Pre-operative Urinalysis Mandatory in Ambulatory Operations in Children
}

\author{
Roland Iheanyichuwu Osuoji ${ }^{1}$, Titilola Awodesu ${ }^{2}$ \\ ${ }^{1}$ Department of Surgery, Lagos State College of Medicine, and The Lagos State University Teaching Hospital, Ikeja, Lagos, Nigeria \\ ${ }^{2}$ Department of Anaesthesia, The Lagos State University Teaching Hospital, Ikeja, Lagos, Nigeria
}

Email address:

drosuoji@yahoo.com (R. I. Osuoji), titilolaawodesu@yahoo.com (T. Awodesu)

\section{To cite this article:}

Roland Iheanyichuwu Osuoji, Titilola Awodesu. A Prospective Study: Is Routine Pre-operative Urinalysis Mandatory in Ambulatory Operations in Children. Journal of Surgery. Vol. 7, No. 6, 2019, pp. 184-187. doi: 10.11648/j.js.20190706.16

Received: October 23, 2019; Accepted: November 14, 2019; Published: November 25, 2019

\begin{abstract}
There are controversies regarding pre-operative routine investigations in ambulatory operations in the paediatric age group. Routinely, patients' packed cell volume (PCV), and genotype were the investigations done for children before surgery, but somewhere along the line, the anaesthesiologists now demand for pre-operative routine urinalysis in children going for ambulatory operations to help detect occult urinary tract diseases. The aim and objectives was to find out the benefits of doing routine preoperative urinalysis and whether it was really necessary in children undergoing ambulatory operations in Lagos, Nigeria"? It was a one year prospective study, carried out from the $1^{\text {st }}$ of September, 2018 to the $31^{\text {st }}$ of August, 2019 in the Lagos State University Teaching Hospital, Ikeja, Lagos, Nigeria. Eighty four children, between the ages of 0 - 12 years, slated for ambulatory operations were mandated to do routine pre-operative urinalysis, routine packed cell volume estimation, and genotype studies. All the children were operated under general anaesthesia. Eighty four children were recruited, comprising of $72(85.7 \%)$ males and $12(14.3 \%)$ females with a male: female ratio of $6: 1$. The patients' age ranged from 0 to 12 years with a mean age of $5 \pm 3 \mathrm{STD}$. An average, minimum and maximum weights of $18.9 \mathrm{~kg}$, $5.0 \mathrm{~kg}$, and $44.0 \mathrm{~kg}$ respectively were recorded, while the average PCV was $34.4 \%$, with a minimum of $26.9 \%$ and maximum of $48.0 \%$. The results of urinalysis were normal in $82.1 \%$ and abnormal in about $17.9 \%$ participants. In the abnormal group, (proteinuria trace $=7$, leucocytes $=4$, nitrites $=2$, proteins + nitrites $=1$, and urobilirubin $=1$ ). All study subjects underwent the procedures successfully with no record of cancellation of any procedure as a result of an abnormal urine finding. We conclude that routine pre-operative urinalysis should be done on all our paediatric ambulatory surgery patients with a view to detecting any abnormalities that may require a follow-up.
\end{abstract}

Keywords: Pre-operative Urinalysis, Children, Ambulatory Surgery

\section{Introduction}

Ambulatory surgery has taken shape in the developed world, and one of the main factors driving this phenomenon is the desire for cost containment $[1,2]$. The modalities to make this successful are being fine-tuned as years go by. However, we may not be able to make a categorical statement about ambulatory operations in Nigeria, where we practice. We routinely did the patients' packed cell volume (PCV), and genotype, but somewhere along the line, the anaesthesiologists now demand for pre-operative routine urinalysis in children going for ambulatory operations to help detect occult urinary tract diseases. This therefore raised the question, "is routine pre-operative urinalysis necessary in children undergoing ambulatory operations in Nigeria"?

We therefore executed this prospective study to document whether there were benefits in doing routine urinalysis in children undergoing ambulatory operations in our hospital.

\section{Patients and Methods}

This was a prospective study that was done in the Lagos University Teaching Hospital (LASUTH), Ikeja Lagos, Nigeria. LASUTH is located in the South-West of Nigeria, and offers free medical services to children between the ages of 0 and 12 years. This study was done from the $1^{\text {st }}$ of September, 2018, to $31^{\text {st }}$ of August, 2019. Ethical clearance was sought and obtained from the institution's Ethics' 
Committee. The authors recruited all children within 0-12 years that were operated as day cases. The various clinical diagnoses in these children included the following: inguinal hernias, undescended testes, thyroglossal cysts, simple superficial lumps, and rectal biopsies for Hirschsprung's disease.

The children were first evaluated clinically in the outpatients' clinics and their parents were counseled and enlightened about the definitive treatment. Also, consents were obtained included urinalysis in their child's preoperative evaluation as well as PCV and genotype (children above 6 months). Children who refused participate and those that had contra-indications for general anaesthesia as decided by the anaesthesiologist were excluded from the study. All study subjects also had an additional pre-operative assessment by the anaesthesiologist, who determined their fitness for general anaesthesia and they were also reassessed on the day of the operation, scrutinizing the urinalysis results. The urinalysis was done in the side laboratory if per adventure it was not carried out before to avoid the cancellation of the operation. The patient was weighed and baseline vital signs taken by the receiving nurses

While on the operating table, monitors were attached to the children and pre-operative vital signs such as the pulse rate, $\mathrm{SpO}_{2}$, ECG were taken and recorded. The children were preoxygenated with $100 \%$ oxygen for $3-5$ minutes and were given intravenous glycopyrollate $4 \mu \mathrm{g} / \mathrm{kg}$ as premedication. Anaesthesia was induced with intravenous Propofol $2 \mathrm{mg} / \mathrm{kg}$, and a Laryngeal Mask Airway (LMA) was inserted after depth of anaesthesia was achieved. Also, endotrachael intubation was done for the children that underwent neck procedures, like Sistrunk's operation for thyroglossal cysts. After the administration of the induction agent, intravenous Propofol $2 \mathrm{~g} / \mathrm{kg}$ and Atracurium $0.5 \mathrm{~g} / \mathrm{kg}$, the children were connected to the anaesthetic machine via the breathing circuit, after ensuring correct placement of the LMA or the endotrachael tube (ETT). The children on LMA breathed spontaneously, while the children on ETT were ventilated. Anaesthesia was maintained with 1.2\% Isoflurane in oxygen, intravenous Fentanyl $1 \mu \mathrm{g} / \mathrm{kg}$ and Paracetamol $20 \mathrm{mg} / \mathrm{kg}$ for the patients on LMA, while intravenous Atracurium was added for the relaxation of the patients on ETT. Intraoperative monitoring of the vital signs was also constantly done.

At the end of the procedure, residual neuromuscular blockage was reversed with IV Neostigmine $0.05 \mathrm{mg} / \mathrm{kg}$, and IV Atropine $0.02 / \mathrm{kg}$ for those that had endotracheal tube placement. The endotracheal tubes were removed when signs of complete recovery from paralysis such as coughing, crying, good head lift, and firm hand grip were noticed. The LMA was also removed when patients were noticed to be fully conscious. The children were transferred to the postanaesthetic care unit for post-operative monitoring of their vital signs. Children were discharged home same day after full recovery, and to be followed up on in the clinic on outpatient basis. At the follow-up clinic, parents were further counseled about the need for a follow-up from an incidental finding in the urinalysis.

\section{Results}

Eighty four children, $72(85.7 \%)$ males and 12 (14.3\%) females with a male: female ratio of 6:1 (Figure 1) were recruited. The age range was 0 to 12 years old. The average, minimum and maximum weights were $18.9 \mathrm{~kg}, 5.0 \mathrm{~kg}$, and $44.0 \mathrm{~kg}$ respectively. The average PCV was $34.4 \%$ with, a minimum of $26.9 \%$ and maximum of $48.0 \%$ (Table 1 ).



Figure 1. Gender distribution of patients.

Table 1. Average age, weight and PCV.

\begin{tabular}{llll}
\hline Parameter & Mean \pm Std. Dev & Minimum & Maximum \\
\hline Age (Years) & $5 \pm 3.0$ & 0 & 12 \\
Weight $(\mathrm{Kg})$ & $18.9 \pm 8.8$ & 5.0 & 44.0 \\
PCV $(\%)$ & $34.4 \pm 3.7$ & 26.9 & 48.0 \\
\hline
\end{tabular}

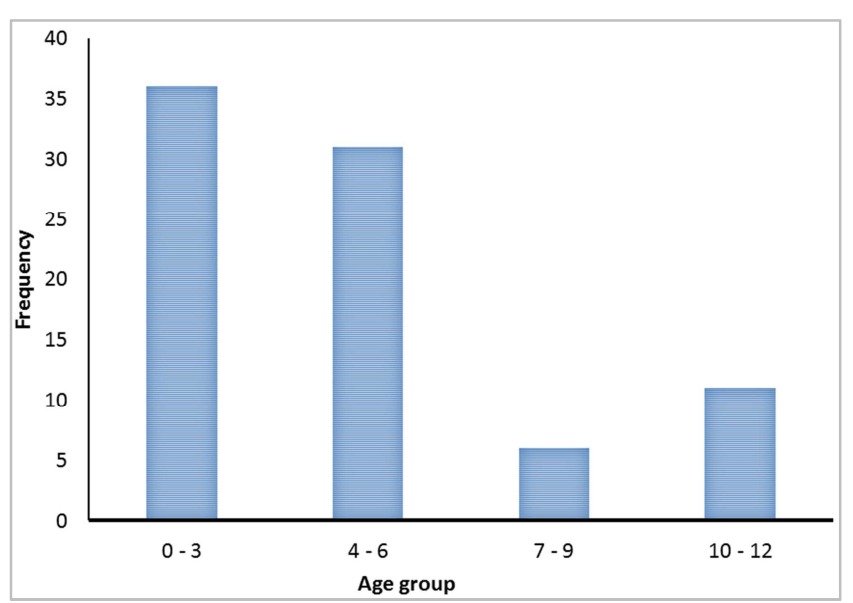

Figure 2. Age group of patients.

The ambulatory operations were performed on predominantly 0 - 6 years $(79.8 \%)$ old children (Figure 2). The results of urinalysis showed $82.1 \%$ normal urine samples and $17.9 \%$ abnormal samples (proteinuria trace $=7$, leucocytes $=4$, nitrites $=2$, proteins + nitrites $=1$, and urobilirubin = 1). The most common clinical diagnoses made were hernias/hydroceles, 40 (47.6\%). Other important diagnoses included undescended testes, $15.5 \%$; hypospadias, $9.5 \%$ (Table 2 ). 
Table 2. Clinical Diagnosis of pediatrics patients prepared for ambulatory operations.

\begin{tabular}{lll}
\hline Diagnosis & Frequency & Percent \\
\hline Hernia/Hydrocoele & 40 & 47.6 \\
Undescended Testes & 13 & 15.5 \\
Hypospadias & 8 & 9.5 \\
Biopsy & 5 & 6.0 \\
Tongue-tie & 5 & 6.0 \\
Meatal stenosis & 4 & 4.8 \\
Redundant prepuce & 2 & 2.4 \\
Thyroglossal cyst & 2 & 2.4 \\
Others & 5 & 6.0 \\
Total & 84 & 100.0 \\
\hline
\end{tabular}

Others: Post Urethroplasty stricture, Lipoma (2), Accessory breast, and Labial agglutination separation

About $79.2 \%$ of male urinalysis were normal and all $(100.0 \%)$ of female results were also normal with no statistically significant difference between male and female urinalysis $p>0.05$ (Table 3 ). The day surgical operations were predominantly performed in males and females of age 0 - 6 with $77.8 \%$ for males and $91.6 \%$ for females. No significant difference was observed between male and female ages, with $\mathrm{p}>0.05$ as the level of significance (Table 4).

Table 3. Gender versus urinalysis findings.

\begin{tabular}{lllll}
\hline \multirow{2}{*}{ Gender (\%) } & Urinalysis & Total & \multirow{2}{*}{$\mathbf{X}^{2}$} & \multirow{2}{*}{$\mathbf{P}$} \\
\cline { 2 - 4 } & Abnormal & Normal & $72(100.0 \%)$ & \\
Male & $15(20.8 \%)$ & $57(79.2 \%)$ & $12(100.0 \%)$ & 3.048 \\
Female & $0(0.0 \%)$ & $12(100.0 \%)$ & $84(100.0 \%)$ & 0.081 \\
Total & $15(17.9 \%)$ & $69(82.1 \%)$ & & \\
\hline
\end{tabular}

Table 4. Sex distribution within age groups.

\begin{tabular}{|c|c|c|c|c|c|c|c|}
\hline \multirow[b]{2}{*}{ Gender } & \multicolumn{4}{|c|}{ Age Category } & \multirow[b]{2}{*}{ Total } & \multirow[b]{2}{*}{$\mathbf{X}^{2}$} & \multirow[b]{2}{*}{$\mathbf{P}$} \\
\hline & $0-3$ & $4-6$ & $7-9$ & $10-12$ & & & \\
\hline Male & $29(40.3 \%)$ & $27(37.5 \%)$ & $6(8.3 \%)$ & $10(13.9 \%)$ & $72(100.0 \%)$ & \multirow{3}{*}{2.073} & \multirow{3}{*}{0.557} \\
\hline Female & $7(58.3 \%)$ & $4(33.3 \%)$ & $0(0.0 \%)$ & $1(8.3 \%)$ & $12(100.0 \%)$ & & \\
\hline Total & $36(42.9 \%)$ & $31(36.9 \%)$ & $6(7.1 \%)$ & $11(13.1 \%)$ & $84(100.0 \%)$ & & \\
\hline
\end{tabular}

\section{Discussion}

As institutions have embarked on cost containment in operations, ambulatory operations have come to stay in most paediatric surgical units $[1,2]$. Some of the cases routinely done on ambulatory basis include herniotomies, which are the most common operations in paediatric surgery [3], orchidopexies, Sistrunk's operation for thyroglossal cysts, and rectal biopsies, for Hirschsprung's disease. These procedures require general anaesthesia. There is a controversy regarding the pre-operative investigations to be carried out on out-patient basis before the child undergoes general anaesthesia in an ambulatory setting. Such investigations include the full blood count, serum urea and creatinine, genotype studies for infants above 6 months of age, chest x-rays, and routine urinalysis. Indeed there is a paucity of literature regarding routine urinalysis in children undergoing ambulatory surgery in our environment. Ugo de Luca et al [1] produced some evidence based guidelines on the feasibility of day surgery in relation to different paediatric surgical procedures, including the pre-operative assessment of the children. The main aspects of pre-operative assessments were discussed among other arms of ambulatory surgery. They noted that $60-80 \%$ of operations in modern paediatric hospitals were performed on a day surgery basis [1, 2]. It is noteworthy that they emphasized that pre-operative investigations (laboratory tests, x-rays, and ECG) were rarely performed, but may be requested by the surgeon during their clinical and anaesthetic evaluation.

In addition, Brennan L J [4], in 1999 suggested that routine pre-operative investigations for children before day surgery was unnecessary in the majority of children undergoing day care surgery are healthy [3], although pre-operative sickle cell screening is still being carried out in the United Kingdom. In other publications [5-7], routine pre-operative laboratory investigations for healthy children were not recommended.

Elliot Kraine et al. [8], while discussing the evaluation of the child for ambulatory surgery, pointed out that the preoperative evaluation is not different from that of the child undergoing in-patient surgery, and includes a full health assessment, physical examination, laboratory testing, where indicated, etc $[7,8]$.

In this study, 84 children that underwent ambulatory operations for various diagnoses, had both abnormal and normal urinalysis pictures, although, all had their operations done without further investigations. If 15 out of 84 urine samples were abnormal, clearly, approximately 18 of every 100 urine samples of paediatric ambulatory surgery children may be abnormal. These children were clinically healthy, but 
had abnormal findings in their urinalysis. They may have had occult renal abnormalities that would require further investigations. Although the theme of this manuscript is not on renal diseases, it is noteworthy to mention that any abnormality detected should be further investigated. Ronit Calderon-Margalit et. al. stated that childhood kidney disease was associated with a significant increased risk of end stage renal disease in adulthood [9]. Also, in 2016, during the World Kidney Day, childhood kidney disease was a point of reference as a source chronic renal disease in childhood and a precursor to kidney disease in adulthood [10]. These abnormal findings were out of serendipity, because the children were clinically healthy. This study agrees with Utsch et. al. that urinalysis in infancy and early childhood is a simple and informative test as long as it is properly done [11].

\section{Conclusion}

We suggest that routine pre-operative urinalysis should be done on all our paediatric ambulatory surgery patients with a view to detecting any abnormalities that may require a follow-up.

\section{References}

[1] Ugo de Luca, Giovanni Mangia, Alessandro Calissi. Guidelines on pediatric day surgery of the Italian Societies of Pediatric Surgery (SICP) and Pediatric Anaesthesiology (SARNePL). Italian Journal of Pediatrics 44; 35 (2018).

[2] Patel RI, Hannallah RS. Laboratory tests in children undergoing ambulatory surgery: a review of clinical and scientific studies. Ambulatory Surgery 8 (2000) 165-169.
[3] Marc I. Rowe, David A, Lloyd, Inguinal Hernia. In Kenneth J. Welch, Judson G. Randolph, James A. O’Neill, Mark I. Rowe (eds). Pediatric Surgery, Mosby Elsevier Year Book Publishers. 1986 pp 779-792.

[4] L. J. Brennan. Modern Day-case Anaesthesia for children. British Journal of Anaesthesia 83 (1); 999: 91-93.

[5] Dr. Pramila Chari, Dr. Indu Sen. Pediatric Ambulatory Surgery- Perioperative concerns. Indian J. Anaesth 2004; 48 (5): $387-393$.

[6] Roy WL, Lerman J, McIntre BG. Is preoperative haemoglobin testing justified in children undergoing elective surgery? Can. J. Anaesth (9) 1991; 38: 700-703.

[7] Fishkin. In Fleisher L. A. Gant J. (ed) Anaesththesiol Clin of North America. Philadelphia WB. Saunders Company 2003; 21: 305-312.

[8] Elliot Krane, Genevieve D'sousa. Guidelines for Paediatric Ambulatory Surgery in Paediatric Anaesthesia and Pain management, Department of Anaesthesia Pain management, Stanford University Medical Center, pp 1-12.

[9] Ronit Calderon-Margalit, Eliezer Golan, Gilad Twig, Adi Leiba, Dorit Tzur, Arnon Afek, et. al. History of Childhood kidney Disease and Risk of Adult End-Stage Renal Disease. N Engl J Med 2018; 378: 428-438. DOI: 10.1056/NEJMoa1700993.

[10] Ingel JR, Kalatar-Zadeh, Schaefer F. Averting the legacy of kidney disease: focus on childhood. Nephrol Dial Transplant 2016; 31: 327-331.

[11] Utsch, B; Klaus, G. Urinalysis in Children and Adolescents. Dtsch Arzte Int 2014; 111: 617-26. DOI: 10.3238/arzteb1.2014.0617. 